\title{
Entrepreneurship e desempenho no setor hoteleiro no Rio de Janeiro: Uma análise empírica utilizando o Índice de Carland
}

\section{Entrepreneurship and performance in the hotel industry in Rio de Janeiro: An empirical analysis using the index of Carland}

\author{
Carlos Renato Fontes Trisciuzzi \\ Universidade Veiga de Almeida \\ e-mail: crft@terra.com.br
}

Heliton J. Ribeiro

Faculdade de Ciências e Tecnologia de Unaí - MG

M.Sc. (UERJ)

Alvaro Vieira Lima

Professor Adjunto da FAF - UERJ

D.Sc. (UFRJ)

Frederico A. de Carvalho

Professor Associado FACC - UFRJ

Artigo Recebido em 19.07.2011. Revisado por pares em 12.11.2011. Recomendado em 12.11.2011 por Edson Roberto Scharf, Editor Responsável. Publicado em 30.06.2012. Organização responsável pelo periódico: FURB Universidade de Blumenau (www.furb.br/rn)

\begin{abstract}
Resumo
O objetivo do trabalho é analisar o efeito de fatores determinantes selecionados sobre o desempenho de uma amostra de estabelecimentos hoteleiros localizados no Rio de Janeiro e em Niterói, com especial atenção ao CEI (Índice de Empreendedorismo de Carland), calculado especificamente para as organizações aqui estudadas. Tal como é tradicional em pesquisas envolvendo fatores determinantes, as perguntas de pesquisa serão respondidas através de abordagem estatística. Uma amostra de conveniência totalizando 150 estabelecimentos foi obtida do universo constituído pelo conjunto de unidades hoteleiras de vários tipos operando na região metropolitana do Rio de Janeiro em 2008. O instrumento de coleta foi um questionário autoadministrado contendo os itens do CEI, além de quesitos demográficos e operacionais. De modo geral, os testes não-paramétricos sobre o CEI confirmaram pesquisas anteriores, destacando-se que não existe correlação entre o CEI e o número de quartos, ou seja, alto potencial empreendedor não é exclusivo de
\end{abstract}

"grandes unidades". Já a equação de regressão estimada mostrou associação positiva e (estatisticamente) significativa com todas as variáveis independentes. Os coeficientes beta indicaram a dominância de variáveis operacionais e o CEI só apareceu na interação com a localização, ajudando a dar sentido ao exercício de regressão.

Palavras-chave: Setor hoteleiro. Potencial empreendedor. Índice de Carland. Regressão múltipla.

\begin{abstract}
The paper tests whether selected variables impact upon the performance of hospitality units located around Rio de Janeiro, Brazil. Special attention is given to CEI, a now widely known and applied index of entrepreneurship. On the basis of a convenience sample of 150 units association hypotheses are tested via multiple regression analysis. Data were collected by means of a selfadministered questionnaire containing the CEI scale plus some easy-to-answer demographic and operational items. When numerically exploring the
\end{abstract}


behavior of the CEI index nonparametric tests confirmed former authors' findings, mainly that CEI is uncorrelated to the number of rooms and normally distributed. Four equations were estimated and most showed very good results. The final equation is commented about and findings showed the dominance of the size variable (number of rooms). Potential entrepreneurship is significant only via its interaction with the location variable but then it may counteract the size effect.

Keywords: Hospitality sector. Entrepreneurship. Carland Index. Multiple regression.

\section{Introdução}

Para Filion (1999, p. 11), a partir dos anos 1980 o campo do empreendedorismo (entrepreneurship) explodiu e foi introduzido em quase todos os domínios das ciências sociais aplicadas. A despeito das controvérsias conceituais e terminológicas e da consequente falta de consenso, sempre reconhecidas na literatura (Jackson; Vaughan, 2005), é visível o grande interesse despertado - dentro e fora da academia - pelos estudos sobre empreendedorismo. Apesar da concordância sobre as dificuldades na obtenção de dados adequados, para alguns autores a principal dificuldade consiste mesmo em (definir e) operacionalizar entrepreneurship de modo consistente e amplamente aceitável (Id., p. 10).

No intuito de contribuir em direção à solução desses dilemas, Carland, Carland e Ensley (2001) propuseram a integração de quatro escalas bastante testadas, mas pouco utilizadas em conjunto. Uma delas, o chamado CEI - Carland Entrepreneurial Index, proposta desde algum tempo antes (Carland; Carland; Hoy, 1992), é calculada empiricamente até hoje, em diversos setores e países (ver, por exemplo, Ferreira; Gimenez; Ramos, 2005, ou Munhon, 2007), e continua sendo considerada uma abordagem bastante adequada à operacionallização do potencial empreendedor. Em sua abrangente pesquisa sobre o que denominaram PPE - Perfil do Potencial Empreendedor, Veit e Gonçalves Jr. (2007,
2008) e Gonçalves Jr., Veit e Gonçalves (2007) também se valeram do CEI para definir seu instrumento de medida.

O objetivo deste trabalho é responder duas perguntas de pesquisa envolvendo o CEI, a saber:

(a) o que se pode dizer sobre o comportamento do Índice de Carland - CEI para uma amostra de unidades hoteleiras na região metropolitana do Rio de Janeiro?

(b) o potencial empreendedor, tal como medido pelo Índice de Carland CEI, afeta o desempenho das unidades hoteleiras amostradas (medido, por exemplo, em termos do número de estrelas atribuído ao estabelecimento)?

A base empírica para propor e testar hipóteses capazes de responder essas perguntas é uma pesquisa quantitativa, realizada na região do Grande Rio, em que foram amostradas 150 organizações hoteleiras, incluindo hotéis, pousadas, hostels e flats. Antes do teste das hipóteses, apresenta-se, ainda, uma exploração empírica sobre o Índice de Carland, apoiada em estatística descritiva e em alguns testes nãoparamétricos. A despeito de já haver grande número de autores, além de Carland e colaboradores, que abordaram quantitativamente o comportamento daquele índice (Gimenez; Inácio Jr., 2002; Inácio Jr., 2002; Ferreira; Gimenez; Ramos, 2005) e seu efeito sobre o resultado empresarial (Gonçalves Filho; Veit; Gonçalves, 2007; Veit e Gonçalves Filho, 2007, 2008), durante a resenha da literatura não foi possível identificar nenhuma investigação semelhante à que foi aqui desenvolvida.

O trabalho está organizado em quatro seções, que se seguem a esta introdução. Na primeira aparece a resenha da literatura, que indica a inspiração e as bases conceituais do estudo. A seguir se expõe a metodologia utilizada e na terceira seção são apresentados os principais resultados obtidos. As conclusões, na quarta seção, completam o texto. 


\section{Resenha da literatura}

Nesta seção se faz uma breve resenha sobre as fontes bibliográficas que sustentam o trabalho. Por diversas razões fazer uma resenha sobre a relação entre empreendedorismo e desempenho organizacional que se pretendesse completa seria tarefa que facilmente ultrapassaria o escopo desse texto, merecendo talvez todo um texto exclusivo. Dentre muitas, quatro razões podem ser apontadas para explicar aquela dificuldade. Primeiro, o tema do empreendedorismo carrega em si múltiplas possibilidades de interpretação, tendo passado do foco no indivíduo (eventualmente) empreendedor ao foco na organização empreendedora. Essa multiplicidade reaparece na resenha elaborada por Ferreira e outros (2010) quando comentam sobre a falta, nos estudos revistos, de uma fundamentação analítica unificada, em particular no que se refere a teorias estabelecidas que tem servido de fundamento a outras disciplinas gerenciais (por exemplo, p. 40).

Em termos de pesquisa empírica aquele percurso leva a fase de operacionalização dos conceitos a passar da busca de características do indivíduo - tais como "perfil empreendedor" (Carland; Carland; Endsley, 2001), "potencial empreendedor" (Ferreira, Gimenez; Ramos, 2005; Gonçalves Filho; Veit; Gonçalves, 2007), ou simplesmente atitudes, motivação ou identidade local - a características organizacionais - tais como "orientação empreendedora" (Rauch et al., 2009; Andersén, 2010; Feng, 2010), "empreendedorismo corporativo" (Zhang et al., 2006), "orientação estratégica empreendedora" (Ferreira, 2007), ou simplesmente tamanho, localização, dentre outros "antecedentes" (Zahra; Jennings; Kuratko, 1999).

Segundo, na fase operacional também não se deve esquecer se o indivíduo cujo eventual "empreendedorismo" se pretende investigar seria o "proprietário" ou "empresário" ou se seriam seus executivos e gerentes. No caso das medidas perceptuais, por exemplo, adverte o autor que gerentes empreendedores tendem a ser mais positivos e otimistas quando ao dessempenho que reportam (ANDERSÉN, 2010, p. 322).

Terceiro, no que se refere à variável dependente - o desempenho - Andersén (2010) alerta para as diferentes conclusões que se seguem a diferentes operacionallizações, contrastando, por exemplo, medidas perceptuais versus medidas objetivas (p. 322-323). Por exemplo, Covin, Green e Slevin (2006), usando medidas objetivas para desempenho, encontraram correlação positiva entre "orientação empreendedora" e crescimento. Em outros estudos a relação era mais nítida quando se empregavam um ou outro dos componentes da variável dependente, evidenciando situações em que ocorre o chamado problema de agregação (ANDERSÉN, 2010, p. 322).

Finalmente, quando se trata da relação entre empreendedorismo e desempenho, há que destacar as observações e sugestões levantadas em resenhas recentes já citadas (Andersén, 2010; Rauch et al., 2009). Segundo Rauch et al. (2009), que examinaram um total de 53 amostras contendo mais de quatorze mil empresas, a correlação entre orientação empreendedora e desempenho é moderadamente alta $(r=$ 0,242 ) e este resultado praticamente não se altera quando se altera a operacionalização dos principais construtos. Estes autores recomendam, ainda, que outros moderadores sejam considerados, para além dos que aqueles estudos trataram (p. 761).

Já Andersén (2010) põe em dúvida a força da relação entre empreendedorismo (medido como "orientação empreendedora") e desempenho, apontando diversos pontos controversos em estudos anteriores por ele revistos. Além disso, a maioria dos estudos tem ignorado a relação entre risco e insucesso, focalizando apenas os aspectos positivos do risk-taking e, portanto, negli- 
genciando o fato de que, tomando riscos, as organizações se deparam com maior risco de insucesso ("failure") (p. 323).

Diante de tais dificuldades e a extensão do tema, a resenha aqui exposta tem caráter seletivo e focalizado, procurando destacar os autores mais próximos à especificidade do tema abordado.

\subsection{Empreendedorismo}

Em uma sociedade empreendedora, aquela que constantemente estimula o espírito empreendedor, os indivíduos considerados empreendedores enfrentam desafios que precisam explorar como uma oportunidade, transformando o aprendizado de empreender na arte de gerar resultados concretos, com disciplina e persistência. São esses indivíduos que impulsionam a economia, provendo novos bens de consumo e criando métodos inovadores de produção (DRUCKER，2003; SCHUMPETER, 1982; TIMMONS, 1989).

Espírito empreendedor ou Empreendedorismo (entrepreneurship) é um termo muito utilizado nas literaturas acadêmicas e profissionais nos dias de hoje, o que, como foi dito, muitas vezes acarreta controvérsias e inconsistências. De acordo com Dornelas (2001), entrepreneurship é derivada da palavra francesa entrepreneur, que significa aquele que assume riscos ou que estabelece ou começa algo novo. No Brasil merece destaque a resenha tão rica, quanto pioneira devida a Araújo (1988), que discute numerosas concepções para o termo.

Para Filion (1999) o campo do empreendedorismo pode ser definido como aquele que estuda os empreendedores, ou seja, examina suas atividades, características, efeitos sociais e econômicos e os métodos de suporte usados para facilitar a expressão da atividade empreendedora.

$\mathrm{Na}$ visão de Carland (1996) e seu grupo de coautores, empreendedorismo é uma integração de cinco elementos: (a) necessidade de realização, (b) criatividade, (c) propensão à inovação, (d) propensão ao risco e (e) postura estratégica voltada à busca de oportunidade.

Para sintetizar, seguindo as principais contribuições presentes na literatura, pode-se concluir que o empreendedorismo individual é uma função de quatro elementos: (i) traços de personalidade (necessidade de realização e criatividade), propensão a (ii) inovação, (iii) ao risco e (iv) postura estratégica (GIMENEZ; INÁCIO Jr; 2002).

\subsection{Perfil empreendedor}

Já há algum tempo o perfil empreendedor dos cidadãos vem despertando o interesse dos governantes e dos órgãos de apoio e fomento, tendo em vista que os Empreendedores invariavelmente estão no centro dos movimentos sociais em resposta às políticas de desenvolvimento econômico e social, por contribuírem diretamente para o crescimento e o progresso.

Nos últimos anos, inúmeros estudos buscaram identificar e, eventualmente, mensurar o perfil empreendedor por meio de estudos e pesquisas empíricas realizadas - principalmente, mas não exclusivamente no meio acadêmico.

A pesquisa anual executada pelo GEM - Global Entrepreneurship Monitor é aplicada em 35 países desde o ano de 2000, e procura identificar a Taxa de Empreendedorismo nos países participantes, considerando os motivos que levam as pessoas a empreender, seja por necessidade ou oportunidade. Nessa pesquisa também são verificadas as condições de competitividade entre os países, os fatores que contribuem para a atividade empreendedora $\mathrm{e}$ as políticas públicas que estimulam a atividade empresarial. (SEBRAE/GEM 2001 a 2006).

Seguindo as lições seminais de Schumpeter (1982 [1934]) - que destacou a figura do empreendedor como associada ao risco, à inovação e ao lucro - alguns autores recentes podem ser destacados por terem iniciado a investigação de cunho mais empírico sobre o comportamento empreendedor, tais como McClelland, que desen- 
volveu uma pesquisa aplicada e identificou uma dezena de características de comportamento empreendedor, comuns às pessoas triunfadoras; e Mintzberg, que propôs a relação entre o empreendedorismo e o processo da estratégia empresarial (GONÇALVES FILHO; VEIT; GONÇALVES, 2007).

Uma vez que raramente o pesquisador está ao lado do empreendedor nos principais momentos do(s) empreendimento(s), torna-se difícil distinguir as características diferenciais, a percepção das oportunidades e dos riscos a elas inerentes; bem como as escolhas estratégicas e a maneira como faz a alocação de recursos na formação e evolução do empreendimento. Trata-se sempre de pesquisas retrospectivas, que procuram recompor a história ou pelo menos a evolução temporal daqueles eventos. Para Andersén (2010), vale a pena lembrar que, em tais recomposições, podem ser usados tanto dados objetivos, quanto perceptuais.

A compreensível falta de uniformidade também tem impedido o progresso dos pesquisadores no sentido de construir uma teoria mais sólida na área, bem como determinar o impacto que a postura empreendedora possa exerce sobre o dessempenho organizacional. (FILION, 1999; DORNELAS, 2001).

\subsection{Mensuração}

A despeito da falta de concordância e da diversidade conceituais, existem diversas tentativas para mensurar o perfil de empreendedor, uma tarefa reconhecidamente difícil por tentar quantificar um construto de cunho subjetivo, para o qual ou sobre o qual não existe um teste ou instrumento universal que pudesse ser considerado "mais completo" ou "mais correto" a este respeito.

No caso brasileiro o interesse por essa mensuração certamente não é novo e existem mesmo propostas originais sobre instrumentos de medida (por exemplo, o IMAE de Lopes Jr. e Souza, 2005).
Dentre tentativas mais anteriores, uma das mais conhecidas se refere ao Carland Entrepreneurship Index (CARLAND, CARLAND; HOY, 1992; 1998), hoje reconhecido tanto do ponto de vista acadêmico, quanto empresarial. O CEI é resultado de longa e abrangente pesquisa sobre empreendedorismo realizada pelo casal James e Joann Carland e diversos colaboradores, tidos como especialistas nesse campo.

Carland e Carland (1996) haviam identificado três características de maior significância na personalidade empreendedora, a saber - a propensão a assumir riscos, a preferência pela inovação e pela criatividade, e a necessidade de realização. Integrados, estes três fatores identificados na pesquisa CEI - Carland Entrepreneurship Index foram utilizados para compor o perfil do empreendedor.

Desde então sua abrangência tem fundamentado a construção de inúmeras pesquisas sobre o potencial empreendedor. O instrumento desenvolvido por Carland, Carland e Hoy (1992) e aperfeiçoado por Carland e Carland (1996) para medir o potencial empreendedor de um indivíduo, por meio do CEI - Carland Entrepreneurship Index vem sendo aprimorado e aplicado em diversos países, incluindo o Brasil (ver, por exemplo, GIMENEZ; INÁCIO Jr.; SUNSIN, 2001; INÁCIO Jr., 2002; GIMENEZ; INÁCIO Jr.; 2002; GONÇALVES FILHO; VEIT; GONÇALVES, 2007; MUNHON, 2007).

Atualmente as quatro dimensões propostas e utilizadas a partir de Carland são relativamente consensuais na literatura empírica sobre empreendedorismo. Numericamente a escala que define o CEI procura detectar a maior ou menor presença desses elementos em um indivíduo, colocando-o em um intervalo de variação de 0 (mais baixo) a 33 (mais alto) pontos. Para dar conteúdo semântico a tais valores, tem sido comum agregá-los em três faixas: (a) Micro-Empreendedor (de 0 a 15 pontos) a 
Entrepreneurship e desempenho no setor hoteleiro no Rio de Janeiro: Uma análise empírica utilizando o Índice de Carland

(c) Macro-Empreendedor (de 26 a 33), passando pela faixa intermediária (b) Empreendedor (de 16 a 25) (GIMENEZ; INACIO Jr.; 2002; GIMENEZ, 2004).

O CEI consiste em um questionário de auto-respostas com trinta e três pares de afirmações, sendo obrigatório ao respondente escolher uma das afirmações em cada par. A experiência empírica tem mostrado que o instrumento requer menos de $10 \mathrm{mi}$ nutos para ser respondido e é de fácil tabulação. Para muitos autores, trata-se de uma ferramenta útil, um indicador que pode auxiliar a avaliar a postura empreendedora individual (GIMENEZ; INÁCIO Jr; 2002).

\subsection{Entrepreneurship e desempenho: a literatura recente}

Antes de passar a uma breve revisão da literatura recente sobre fatores determinantes do desempenho organizacional, especialmente quando se inclui o papel do empreendedorismo, cabe mencionar alguns aspectos relativos à relação bivariada entre entrepreneurship e performance. De fato, desde Schumpeter se acredita que uma característica essencialmente individual tal como o empreendedorismo - possa levar não apenas uma organização ao sucesso, mas também toda a economia e toda a sociedade (SCHUMPETER, 1982 [1934]; TIMMONS, 1989). Esta crença evoca dois aspectos que têm consequências imediatas em termos de pesquisa empírica. Primeiro, gradativamente o empreendedorismo passou de característica individual a organizacional, possibilitando seu estudo a partir de amostras de empresas e não apenas de empreendedores, gerentes ou empregados. Segundo, passaram a aparecer e a despertar interesse não somente as propostas sobre como medir o desempenho organizacional, quanto as que se referiam a operacionalizar o constructo entrepreneurship, agora um dos determinantes desse desempenho.

A delimitação da literatura a ser revista a obras mais recentes foi justificada mais acima pela existência de diversas resenhas, tais como Andersén (2010), e pela metaanálise efetuada por Rauch et al. (2009). Todos os autores ali revistos abordaram ou anteciparam questões que reapareceram no presente trabalho, especialmente as que dizem respeito aos procedimentos metodológicos e ao escopo dos resultados.

$\mathrm{Na}$ literatura pode-se encontrar, ainda, o exame da influência de outras características individuais ou organizacionais tais como estilo gerencial, aspectos étnicos, formação para empreender, localização ou estágio no ciclo de vida - sobre o desempenho da organização em que atuam os indivíduos.

No caso do setor hoteleiro, pode-se mencionar os trabalhos de Feuerschutte (2007), Honma (2007), Morrison (2006; setor de hospitalidade), e Pedrosa e Santos (2008).

\section{Metodologia}

Como já foi mencionado, o objetivo deste trabalho é responder duas perguntas de pesquisa relativas ao comportamento do CEI - Índice de Empreendedorismo de Carland, a saber:

(a) o que se pode dizer sobre o comportamento do Índice de Carland CEI para uma amostra de unidades hoteleiras na região metropolitana do Rio de Janeiro?

(b) o potencial empreendedor, tal como medido pelo Índice CEI de Carland, afeta o desempenho das unidades hoteleiras amostradas (medido, por exemplo, em termos do número de estrelas atribuído ao estabelecimento)?

\subsection{Coleta e tratamento dos dados}

O universo da pesquisa é o conjunto dos estabelecimentos hoteleiros na região do Grande Rio, que inclui essencialmente a capital fluminense e o município de Niterói. Uma amostra de conveniência contendo 150 unidades foi obtida do universo; neste caso a conveniência se refere à facilidade 
de acesso e/ou a concordância em participar da pesquisa. O respondente escolhido para aplicação do questionário foi $\mathrm{o}$ principal executivo do estabelecimento que assim se identificasse ou alguém por ele indicado para a tarefa

O desempenho será medido pela variável dependente numérica representando o Número de Estrelas atribuídas ao estabelecimento hospedeiro. Para explicar seu comportamento, de preferência, a escolha das variáveis independentes (ou explicativas) deve basear-se em uma relação teoricamente determinada. No presente caso não parece haver qualquer teoria prontamente disponível para explicar a variável dependente escolhida. Assim sendo foi aqui utilizada uma abordagem descritiva (Phlips; Blomme, 1973), ad hoc e parcimoniosa, apoiada em argumentos "razoáveis", nem todos necessariamente justificados por (ou presentes em) alguma teoria.

Para coletar os dados, o questionário foi elaborado a partir da recomendação de Carland (1996). A versão em português se baseia em pesquisa anterior de Gimenez e Inácio Jr. (2002). Segundo os autores, o "trabalho indicou que a versão traduzida provou ser útil para a mensuração do potencial empreendedor e, de maneira geral, alcançou bons níveis de validade e confiabilidade" (p. 112).

Foram, ainda, acrescentados itens relativos a algumas variáveis operacionais e demográficas de fácil coleta, que aparecem no Quadro 1.

Uma breve digressão sobre a escolha da variável dependente se faz necessária. Desde logo cabe reconhecer que a literatura fornece um grande número de alternativas para medir o desempenho organizacional. $\mathrm{Na}$ presente pesquisa de campo, porém, se pretendia manter o levantamento de informações tão simples quanto possível. Pelo fato de atender este requisito de conveniência, o Número de Estrelas apareceu como alternativa interessante e acessível. Conforme explicado e divulgado no site da $\mathrm{ABIH}$ - Associação Brasileira da Indústria de Hotéis (www.abih.com.br), o Manual de Classificação dos meios de hospedagem expõe regras e critérios minuciosos para definir a atribuição de estrelas a um estabelecimento, cobrindo a avaliação física, a avaliação da gestão, do atendimento e dos serviços, os aspectos legais, de segurança, de saúde e higiene, e inúmeros itens específicos. Embora pareça adotar uma "lógica interna" quanto ao "sucesso" da organização hoteleira, tais critérios parecem indicar dimensões que se correlacionam tanto com a estrita rentabilidade, quanto com aspectos de eficiência e eficácia.

Por outro lado, a escolha de todas essas variáveis listadas no Quadro 1 procurou ser parcimoniosa por dois motivos principais. Primeiro, nas primeiras explorações estatísticas a correlação entre CEI e desempenho foi muito baixa, indicando que a equação explicativa deveria ser ampliada, mas não tanto a ponto de impedir que algum poder explicativo do índice CEI viesse à tona. Segundo porque, mesmo no caso dos hotéis, a maior parte dos estabelecimentos, sendo empresas familiares ou de pequeno porte (ou ambos), encara com desconfiança e certa má vontade a atividade de "pesquisa" ou até mesmo de simples levantamento de dados.

Os questionários foram enviados $\mathrm{e}$ recebidos pelos pesquisadores, tanto por telefone, quanto pessoalmente, como fosse mais fácil, dependendo do estabelecimento. Por diversas vezes o levantamento direto feito no estabelecimento, foi acompanhado de um follow up telefônico para agradecer a participação e/ou checar alguma informação. Outras vezes a visita ocorreu após um primeiro levantamento telefônico e visava verificar in loco certas características da unidade e confirmar a compreensão do respondente acerca do questionário. No total a pesquisa de campo durou entre novembro de 2008 e janeiro de 2009 , tendo 
Entrepreneurship e desempenho no setor hoteleiro no Rio de Janeiro: Uma análise empírica utilizando o Índice de Carland

sido entrevistados 150 unidades de hospedagem no Grande Rio.

Os resultados serão analisados em dois movimentos. Primeiro, tomam-se por base as freqüências relativas e algumas estatísticas descritivas univariadas das variáveis referentes aos temas escolhidos para compor o perfil dos respondentes acerca das características e atributos de interesse. Para completar a análise univariada serão aplicados alguns testes não-paramétricos, dados a natureza e o tamanho da amostra.

Tabela 1 - Variáveis da Pesquisa

\begin{tabular}{|c|c|c|c|c|}
\hline Nome & Usada como & Definição & Escopo & $\begin{array}{c}\text { Sinal } \\
\text { esperado }\end{array}$ \\
\hline Número de Estrelas & $\begin{array}{l}\text { Dependente } \\
\text { numérica }\end{array}$ & $\begin{array}{l}\text { Número de estrelas do } \\
\text { estabelecimento }\end{array}$ & Desempenho & (nsa) \\
\hline Número de Quartos & $\begin{array}{l}\text { Independente } \\
\text { numérica }\end{array}$ & $\begin{array}{l}\text { Número total de quartos oferecidos no } \\
\text { estabelecimento }\end{array}$ & Operacional & + \\
\hline $\begin{array}{c}\text { Natureza do } \\
\text { estabelecimento }\end{array}$ & $\begin{array}{l}\text { Independente } \\
\text { dummy }\end{array}$ & Hotel $=1 ;$ outros $=0$ & \multirow{2}{*}{ Demográficas } & + \\
\hline Local & $\begin{array}{l}\text { Independente } \\
\text { dummy }\end{array}$ & $\begin{array}{l}\text { Cidade do Rio de Janeiro }=1 \text {; Fora do } \\
\qquad \text { Rio }=0\end{array}$ & & + \\
\hline $\begin{array}{c}\text { CEI - Índice de } \\
\text { Carland }\end{array}$ & $\begin{array}{l}\text { Independente } \\
\text { numérica }\end{array}$ & Índice de Empreendedorismo & Atitude & $?$ \\
\hline
\end{tabular}

As técnicas não-paramétricas são particularmente adequadas aos dados das ciências do comportamento. A aplicação dessas técnicas não exige hipóteses quanto à distribuição da população da qual se tenha retirado amostras; em geral, tais hipóteses são restritivas e raramente se verificam para aqueles dados. Além disso, a estatística não-paramétrica pode ser aplicada a dados que estejam medidos apenas como ordenações, ou mesmo, em certos casos, para estudo de variáveis nominais (FONSECA; MARTINS, 1996). De acordo com Siegel (1981, p. 34), as principais vantagens dos testes não-paramétricos são que: (a) não é necessário especificar condições sobre os parâmetros da população da qual se extrai a amostra; (b) não se exigem mensurações tão restritas quanto o que ocorre no caso paramétrico; e (c) as hipóteses, no caso nãoparamétrico, ocorrem em menor número e são menos restritivas do que no caso para- métrico.

No segundo movimento da análise é aplicado um modelo de regressão múltipla (Hair Jr. et al., 1998, cap. 4; Gujarati, 1988, caps. $7,8,10$ e 14) para testar hipóteses sobre a ocorrência de associações estatisticamente significativas, conforme explicado antes. Os modelos de regressão múltipla têm longa tradição nas aplicações da Estatística a problemas reais e durante muito tempo, devido a limitações computacionais, foram a grande opção na maioria das aplicações "práticas" de técnicas multivariadas. Conforme Hair e outros (1998, p. 161), a regressão múltipla fornece uma forma de avaliar objetivamente o grau e natureza da associação entre uma variável dependente e várias outras independentes ou explicativas. A interpretação mais direta para o uso da equação de regressão é a determinação da importância relativa de cada variável independente. 
Na presente aplicação da regressão múltipla cabe recordar a distinção proposta por Phlips e Blomme (1973). De acordo com esses autores, naquela versão que chamam de "regressão linear descritiva", a análise de regressão pode ser aplicada mesmo quando a equação estimada é olhada como resultado simplesmente numérico, embora otimamente ajustada no sentido, por exemplo, do método dos mínimos quadrados. Nesses casos, os coeficientes de regressão são meros parâmetros descritivos, sem qualquer elo com alguma teoria prévia.

Após a escolha da equação final foi aplicado o teste de White para detectar a presença de heteroscedasticidade, que, em caso afirmativo, invalidaria a utilização do método dos Mínimos Quadrados Ordinários (MQO).

\subsection{Limitações da pesquisa}

Tendo em vista que o processo de seleção foi determinado pela conveniência, a amostra, embora independente, não foi aleatória. Devido à presença e/ou ao follow up dos pesquisadores, todas as perguntas foram completamente respondidas, mas não foi possível apurar o Número de Estrelas de um dos estabelecimentos. Assim a amostra efetiva contará com 149 dos 150 entrevistados. O único valor faltante será "descontado" nos graus de liberdade da regressão, mas esta diminuição pode ser tolerada diante dos objetivos da pesquisa.

A coleta foi realizada em meses do verão, de modo que, apesar do foco no CEI, que requer a resposta a 33 pares de itens dicotômicos mutuamente exclusivos $(\operatorname{sim}=$ 1; não $=0$ ), o questionário aplicado era relativamente simples, já que era necessário fazer um levantamento acessível aos respondentes e por isso mesmo pouco demorado. Neste tipo de instrumento de pesquisa facilita-se a padronização de pontos de vista, em detrimento das nuances e das especificidades. Quando não se utilizam perguntas abertas para complementar a informação coletada - que não foram utili- zadas aqui - pode-se ficar limitado aos aspectos mais superficiais do problema de pesquisa.

Nos casos em que não foi possível a presença do entrevistador, o respondente recebia o questionário por e-mail, fazendose a seguir um follow up destinado a facilitar o preenchimento e a garantir a efetiva entrega das respostas. Apesar de todos os cuidados, pode ter havido alguma distorção nas respostas, devido à dificuldade de entrevistar o "verdadeiro" empreendedor da organização, especialmente nas grandes unidades. Assim pode-se considerar que, a rigor, o público-alvo desta pesquisa foi composto dos executivos principais das empresas amostradas. De todo modo, segundo Pedrosa e Souza (2008), gerentes com atitude empreendedora são fontes de diferencial competitivo e promotores do desenvolvimento empresarial, fundamentais para o setor hoteleiro (p. 2).

Segundo a literatura recente, a limitação quanto ao aspecto de a amostra conter apenas estabelecimentos em atividade e, portanto, ainda fora da situação de insucesso, é compartilhada com a maioria dos estudos de autores euroamericanos (ANDERSÉN, 2010).

\section{Resultados}

O questionário foi apresentado pessoalmente ou por internet entre novembro de 2008 e janeiro de 2009 e as respostas foram aceitas até 08 de fevereiro de 2009. Todos os 150 questionários enviados foram considerados válidos para os objetivos da pesquisa e constituem a amostra final. Não existem dados faltantes para nenhuma das variáveis presentes no quadro 1, exceto para o número de estrelas de uma das unidades, de modo que nas estimações das equações de regressão conta-se com 149 observações, uma alteração considerada aceitável para efeitos do estudo executado. 


\subsection{Perfil da amostra}

Segundo os dados mais atualizados contidos no Anuário Estatístico do Estado do Rio de Janeiro (CIDE, 2006), a população de estabelecimentos de hospedagem ("alojamentos") no Rio de Janeiro possuía um total de 2045 unidades, distribuídas conforme a Tabela 1. A região composta pelas cidades do Rio de Janeiro e Niterói concentra cerca de $48 \%$ do total de estabelecimentos.

A amostra não aleatória aqui considerada representa, então, cerca de $16,3 \%$ do total de estabelecimentos na região composta por Niterói e Rio de Janeiro. Considerando o tipo de alojamento (natureza do estabelecimento), os hotéis representaram cerca de $82 \%$ das respostas totais, contra 57\% na Tabela 1. Coube às pousadas cerca de $11 \%$ e aos hostels $5 \%$; havendo apenas 3 flats na amostra (2\%). Os estabelecimentos não-hoteleiros somam então $17 \%$ contra $43 \%$ na tabela 1 .

Tabela 2 - Estabelecimentos hoteleiros, por tipo, segundo Regiões de Governo no RJ

\begin{tabular}{l|llll}
\hline $\begin{array}{l}\text { Regiões de } \\
\text { Governo- } \\
\text { RJ }\end{array}$ & $\begin{array}{c}\text { Estabele- } \\
\text { cimentos } \\
\text { hoteleiros } \\
\text { (a) }\end{array}$ & $\begin{array}{c}\text { Outros } \\
\text { tipos de } \\
\text { aloja- } \\
\text { mento }\end{array}$ & $\begin{array}{c}\text { To } \\
\text { tal } \\
\text { (b) }\end{array}$ & $\begin{array}{c}\text { \% } \\
\mathbf{1 0 0 ( a /} \\
\text { b) }\end{array}$ \\
\hline $\begin{array}{l}\text { Estado do } \\
\text { RJ }\end{array}$ & 1561 & 484 & 20 & 76,3 \\
$\begin{array}{l}\text { Região } \\
\text { Metropo- } \\
\text { litana }\end{array}$ & 695 & 541 & 12 & 56,2 \\
$\begin{array}{l}\text { Rio de } \\
\text { Janeiro }\end{array}$ & 507 & & 36 & $\%$ \\
Niterói & 48 & 382 & 88 & 57,0 \\
& & 40 & 88 & 54,5 \\
\hline
\end{tabular}

Fonte - baseada em CIDE (2006)

Em termos de localização, a maioria (72\%) das unidades localizou-se na cidade do Rio de Janeiro - contra $43 \%$ na Tabela 1 - distribuindo-se no total da cidade entre os bairros da zona sul $(92 \%)$ e centro $(8 \%)$. As demais unidades $(28 \%)$ situaram-se em Niterói (4\% na Tabela 1).

Para as variáveis Número de Quartos e Número de Estrelas houve 32 res- postas faltantes, totalizando 118 respostas válidas. Considerando este total, os quartis da distribuição do Número total de Quartos indicam que no primeiro quartil estão os estabelecimentos que possuem até 49 quartos, ficando no último quartil os estabelecimentos com mais de 95 quartos. O número médio de quartos foi igual a 78,4, a mediana igualou a moda em 70 quartos . O desvio-padrão alcançou 49,57 o que dá um coeficiente de variação (CV) de 63,2\%.

Em termos de desempenho, aproximado pelo Número de Estrelas, a maioria das unidades (a moda, ou seja, a classe de maior freqüência) possui 3 estrelas. A média foi de 2,65 e a mediana igualou 3 estrelas. $\mathrm{O}$ desvio ficou igual a 1,36 e o $\mathrm{CV}=$ $51,3 \%$.

Assim, a amostra é ligeiramente mais homogênea em desempenho do que em tamanho. Isto provavelmente vai refletir-se na dificuldade de que o tamanho pudesse explicar sozinho a variação no desempenho, a despeito da relação definicional entre tamanho e estrelas.

\subsection{Comportamento do índice de Carland (CEI)}

Em consonância aos objetivos do estudo, esta subseção destaca os resultados para o índice CEI. Na amostra estudada os valores do índice de empreendedorismo variaram entre 7 e 27 pontos, com média de 18,44, moda igualando a mediana em 19 pontos. Em termos da categorização em faixas de valores, resultou que os Microempreendedores corresponderam a $17 \%$ da amostra; os Empreendedores, a cerca de $82 \%$ e os Macro-empreendedores, a pouco mais de $1 \%$, o que equivale ao que foi encontrado em outros estudos (por exemplo, CULTI-GIMENEZ e outros, 2006).

Quanto aos testes não-paramétricos envolvendo o CEI, foram obtidos os seguintes resultados:

(a) Pelo teste de Kolmogorov-Smirnov (Siegel, 1975, cap. 4), podemos aceitar que CEI segue uma distribuição Normal. Esta 
verificação tornou-se praxe nos exercícios envolvendo o CEI (ver Gimenez e Inácio Jr. (2002), embora a hipótese de normalidade não seja a rigor requerida para uma boa aplicação do método dos MQO (Mínimos Quadrados Ordinários).

(b) Pelo teste de Mann-Whitney (Siegel, 1975, p. 131-144) o comportamento do índice CEI não está associado a nenhuma das seguintes variáveis

(i) Natureza (ser ou não hotel) - houve valores altos e baixos tanto para hotéis, quanto para as demais categorias;

(ii) Local (estar ou não localizado na cidade do Rio) - houve valores altos e baixos tanto para estabelecimentos da capital, quanto para as unidades localizadas em Niterói.

(c) Pelo teste do coeficiente de correlação ordinal (versões Spearman e Kendall, cf. Siegel, 1975, cap. 9) não existe correlação entre CEI e número de quartos ("tamanho" da unidade ), ou seja, alto CEI não é "exclusivo das grandes unidades". Este resultado é extremamente útil porque significa que quaisquer indícios de colinearidade não devem ser atribuídos ao índice CEI, que, por isso, não fica ameaçado de exclusão da equação, pelo menos não por aquela razão. Assim o objetivo do exercício com respeito ao estudo de CEI na amostra fica preservado.

\subsection{Teste da hipótese}

A primeira equação estimada contemplou o modelo completo contendo todas as variáveis originalmente consideradas no quadro 1. Apesar de os resultados terem sido muito bons em termos estatísticos tanto pelo $\mathrm{R}^{2}$, quanto pelos p-valores das estatísticas $\mathrm{t}$ e $\mathrm{F}$ e pelos sinais esperados o coeficiente padronizado de CEI ficou muito reduzido, conforme mostrado na Tabela 2.

$\mathrm{Na}$ tentativa de investigar se a influência do CEI poderia ser melhorada, estimou-se então uma equação que incluiu todas as dummies de coeficiente angular, ou seja, as interações (produtos) entre as
Tabela 3 - Resultado da regressão múltipla *

\begin{tabular}{|c|c|c|c|c|c|}
\hline & Coefic & ntes & \multirow{3}{*}{$\begin{array}{l}\text { Coefici- } \\
\text { entes } \\
\text { Padroni- } \\
\text { zados }\end{array}$} & \multirow{2}{*}{$\begin{array}{l}\mathrm{T} \\
\text { calcu- } \\
\text { lado }\end{array}$} & \multirow{2}{*}{$\begin{array}{l}\text { p- } \\
\text { va- } \\
\text { lor }\end{array}$} \\
\hline $\begin{array}{l}\text { VARI- } \\
\text { ÀVEIS }\end{array}$ & B & Erro & & & \\
\hline $\begin{array}{c}\text { Constant } \\
\mathrm{e}\end{array}$ & $-0,671$ & $\begin{array}{c}0,32 \\
1\end{array}$ & & $-2,092$ & $\begin{array}{l}0,0 \\
38\end{array}$ \\
\hline $\begin{array}{l}\text { Número } \\
\text { Quartos }\end{array}$ & 0,012 & $\begin{array}{c}0,00 \\
1\end{array}$ & 0,421 & 9,092 & $\begin{array}{c}0,0 \\
00\end{array}$ \\
\hline $\begin{array}{l}\text { HOTEL } \\
\text { ou NÃOO }\end{array}$ & 1,891 & $\begin{array}{c}0,17 \\
1\end{array}$ & 0,536 & 11,088 & $\begin{array}{c}0,0 \\
00\end{array}$ \\
\hline $\begin{array}{l}\text { RIO ou } \\
\text { NÃO }\end{array}$ & 0,249 & $\begin{array}{c}0,13 \\
8\end{array}$ & 0,083 & 1,802 & $\begin{array}{l}0,0 \\
74\end{array}$ \\
\hline CEI & 0,034 & $\begin{array}{c}0,01 \\
6\end{array}$ & 0,084 & 2,098 & $\begin{array}{l}0,0 \\
38\end{array}$ \\
\hline
\end{tabular}

* - Variável Dependente = Número de Estrelas; $\mathrm{R}^{2}$ ajust $=0,765 ; \mathrm{F}=121,562, \mathrm{p}<0,1 \%$.

dummies de natureza e local e as outras duas variáveis independentes - o Número de Quartos e o Índice CEI de Carland. Quando se consideram as interações, o efeito modelado para o CEI pode variar entre as categorias definidas pelas dummies, por exemplo, segundo a localização. Este recurso permite, então, que a equação estimada expresse relações mais realistas quanto ao papel do CEI.

Nesta nova especificação, embora mostrando resultados instrutivos nas interações envolvendo CEI e ligeiramente melhores em termos de $\mathrm{R}^{2}$, alguns $\mathrm{p}$-valores deixaram de ser estatisticamente significativos (Tabela 3 ), incluindo o da variável que mais nos interessa - o CEI de Carland. Além disso, como era de esperar (Blalock, 1972, p. 463-464), introduziu-se colinearidade entre as variáveis, de tal forma que três dos condition indexes superaram o valor de 60, muito acima do valor máximo recomendado de 30 (Gujarati, 1988, p. 301). Vale acentuar, como foi apontado antes, que a presença de colinearidade não deve ser atribuída ao índice CEI.

Para sanar este problema decidiu-se então - em consonância com a abordagem descritiva (Phlips e Blomme, 1973) aqui adotada para o exercício de regressão - 
Entrepreneurship e desempenho no setor hoteleiro no Rio de Janeiro: Uma análise empírica utilizando o Índice de Carland

explorar o caminho da regressão stepwise (versão backward). Os resultados obtidos (Tabela 4) podem ser considerados bons em termos de $\mathrm{R}^{2}$ e de coeficientes significantes, embora o procedimento backward tenha eliminado CEI, que só aparece em uma interação com a dummy de Local.

Persistiu, no entanto, um condition index elevado $(51,232)$ e uma última especificação foi tentada pela eliminação da variável com maior VIF (variance inflation factor; ver Judge et al., 1988, p. 869). Os resultados desta versão (Tabela 5), considerados muito aceitáveis, constituem a ver- são final do exercício empírico e serão comentados a seguir.

De modo geral, esses resultados finais foram muito bons em termos dos objetivos do estudo e diversos aspectos merecem destaque. Primeiro, o teste F para significância da equação foi significativo a menos de $0,1 \%$, mostrando que a equação é melhor do que simplesmente a média da variável dependente para explicar sua variação.

Segundo, o valor de 0,802 obtido para $\mathrm{R}^{2}$ (ajustado para graus de liberdade) pode ser considerado muito bom, em se tratando de uma amostra em cross section.

Tabela 4 - Resultado da regressão múltipla com interações *

\begin{tabular}{|c|c|c|c|c|c|}
\hline & \multicolumn{2}{|c|}{ Coeficientes } & \multirow{2}{*}{$\begin{array}{l}\text { Coeficientes } \\
\text { Padronizados }\end{array}$} & \multirow{2}{*}{ T calculado } & \multirow{2}{*}{ p-valor } \\
\hline VARIÁVEIS & B & Erro & & & \\
\hline Constante & $-1,170$ & 0,976 & & $-1,198$ & 0,234 \\
\hline Num Quartos & 0,036 & 0,010 & 1,327 & 3,778 & 0,000 \\
\hline CEI & 0,018 & 0,051 & 0,042 & 0,342 & 0,733 \\
\hline HOTEL ou NÃO & 3,635 & 1,172 & 0,986 & 3,101 & 0,002 \\
\hline RIO ou NÃO & $-1,234$ & 0,948 & $-0,396$ & $-1,301$ & 0,196 \\
\hline LOC_ROOM & $-0,011$ & 0,005 & $-0,470$ & $-2,154$ & 0,033 \\
\hline NAT_ROOM & $-0,015$ & 0,009 & $-0,614$ & $-1,644$ & 0,103 \\
\hline LOC_CEI & 0,113 & 0,052 & 0,704 & 2,182 & 0,031 \\
\hline NAT_CEI & $-0,075$ & 0,066 & $-0,407$ & $-1,127$ & 0,262 \\
\hline
\end{tabular}

* - Variável Dependente $=$ Número de Estrelas; $\mathrm{R}^{2}$ ajust $=0,804 ; \mathrm{F}=61,125 ; \mathrm{p}$-valor $<0,1 \%$.

No entanto, nosso principal objetivo não era explicar, nem prever o comportamento dessa variável, mas sim descobrir relações significativas entre ela e algumas outras variáveis selecionadas.

Olhando os coeficientes padronizados, a maior influência sobre o desempenho voltou a ser da variável "Tamanho" (o Número de Quartos), seguida, com intensidade semelhante e sinais contrários, pela dummy de natureza e pela interação entre Local e Tamanho (medido pelo Número de Quartos).
Quarto, o índice CEI de Carland só aparece na equação através da interação com local, indicando que a localização no Rio favorece maior influência do potencial empreendedor sobre o desempenho (em termos de estrelas).

Pelo valor do coeficiente beta, esta é a variável que menos impacta o desempenho.

Mesmo assim, combinando os dois últimos resultados pode-se concluir que, nos estabelecimentos hoteleiros localizados no Rio, a influência (positiva) do potencial 
empreendedor mais do que compensa a do Número de Quartos.

Finalmente, pelo teste de White (Kennedy, 1998, p. 134) pode-se aceitar a hipótese de ausência de heteroscedasticidade, a um nível de significância menor que $0,5 \%$, indicando que a eficiência do estimador de Mínimos Quadrados Ordinários, aqui utilizado, pode ser considerada garan- tida. Mesmo assim, as altas significâncias indicada pelos $\mathrm{p}$-valores, que aparecem na última coluna da tabela, devem ser olhadas com cautela já que, devido ao uso do procedimento stepwise, todas devem estar superestimadas.

Tabela 5 - Resultado da regressão múltipla backward

\begin{tabular}{l|cccccc}
\hline & \multicolumn{2}{|c}{ Coeficientes } & & Coeficientes Padronizados & T calculado & p-valor \\
& B & Erro & & & & \\
VARIÁVEIS & $-0,935$ & 0,275 & & $-3,403$ & 0,001 \\
Constante & 0,038 & 0,009 & & 1,392 & 4,082 & 0,000 \\
Num quartos & 2,309 & 0,314 & 0,626 & $-0,496$ & 7,360 & 0,000 \\
HOTEL ou NÃO & $-0,011$ & 0,004 & $-0,661$ & $-2,852$ & 0,005 \\
LOC_ROOM & $-0,017$ & 0,009 & 0,013 & 0,300 & $-1,797$ & 0,075 \\
NAT_ROOM & 0,048 & 0,013 & & 3,618 & 0,000 \\
\hline LOC_CEI & & & & & & \\
\hline
\end{tabular}

* - Variável Dependente $=$ Número de Estrelas; $\mathrm{R}^{2}$ ajust $=0,806 ; \mathrm{F}=98,221 ; \mathrm{p}$-valor $<0,1 \%$.

Tabela 6 - Regressão múltipla - versão final

\begin{tabular}{c|ccccc}
\hline & & & & & \\
& & & & & \\
& & & & & \\
VARIÁVEIS & Coeficientes & Erro & Coeficientes Padronizados & T calculado & p-valor \\
\hline Constante & $-0,576$ & 0,191 & & $-3,021$ & 0,003 \\
Num quartos & 0,023 & 0,004 & 0,840 & 5,636 & 0,000 \\
HOTEL ou NÃO & 1,868 & 0,197 & 0,507 & 9,467 & 0,000 \\
LOC_ROOM & $-0,013$ & 0,004 & $-0,545$ & $-3,150$ & 0,002 \\
LOC_CEI & 0,051 & 0,013 & 0,317 & 3,818 & 0,000 \\
\hline
\end{tabular}

* - Variável Dependente = Número de Estrelas; $\mathrm{R}^{2}$ ajust =0,802; F=119,609; p-valor $<0,1 \%$.

\section{Conclusões}

Este trabalho investigou alguns aspectos do comportamento do CEI Carland Entrepreneurship Index para uma amostra de 150 unidades hoteleiras na cidade do Rio de Janeiro. Foram utilizadas duas linhas de investigação empírica.

A primeira elaborou uma análise descritiva, baseada em estatísticas uni- e bivariadas sobre o índice, calculadas a partir das respostas a questões selecionadas do questionário utilizado na coleta de dados. Esta parte se justificou por ter produzido números até então desconhecidos a respeito da produção de serviços hoteleiros no Rio de Janeiro. Por exemplo, na amostra estudada os respondentes estão concentrados na categoria chamada Empreendedor, como já ocorreu em outros estu- 
dos. Além disso, o índice CEI não está correlacionado nem com o "tamanho" do estabelecimento, nem com sua localização, ilustrando a idéia de que o espírito empreendedor independe das facilidades proporcionadas por economias de escala ou pelos recursos ambientais existentes. A confirmação da normalidade do CEI, apontada por Carland desde 1992, está de acordo com resultados de outros pesquisadores (por exemplo, Gimenez; Inácio Jr.; 2002).

A segunda linha investigativa consistiu na estimação de quatro equações de regressão múltipla descritiva (Phlips; Blomme, 1973) para analisar a influência do CEI sobre o desempenho das empresas respondentes, medido pelo número de estrelas do estabelecimento pesquisado. Em busca de uma representação adequada e interessante para o efeito do CEI sobre o desempenho, partiu-se de uma equação em que esse efeito aparecia isoladamente. Nesta primeira equação, apesar de o coeficiente do CEI ter sinal adequado e ser significativo ( $\mathrm{p}$-valor $=0,038)$, o efeito do CEI foi considerado muito baixo. Passando a outras tentativas, que contemplaram interações entre o CEI e as dummies de natureza e de local, foi necessário corrigir alguns problemas daí decorrentes, chegando, finalmente, a uma especificação satisfatória que aparece na Tabela 5.

Esse tipo de análise sobre o CEI ainda não havia sido observado nas literaturas nacional e internacional resenhadas, embora haja modelagens mais avançadas do que a presente quanto à relação entre potencial empreendedor e resultado empresarial, tais como em Veit e Gonçalves Filho (2007, 2008) e em Gonçalves Filho, Veit e Gonçalves (2007). No presente trabalho a regressão múltipla foi considerada adequada, visto que não são utilizadas medidas perceptuais, salvo o próprio CEI.

Os resultados obtidos confirmaram a significância estatística e o sinal dos coeficientes estimados, bem como a dominância da influência do Número de Quartos ("tamanho"). Aliás, uma consequência disso foi que a influência do CEI foi significativa apenas sob forma de interação com a localização e com sinal negativo, indicando que o ambiente de negócios oferecido na cidade do Rio de Janeiro permite que o espírito empreendedor influencie positivamente o desempenho. A despeito da natureza e do tamanho da amostra utilizada, esta conclusão chama atenção para os benefícios que políticas "localizadas" podem representar em termos de liberar ou viabilizar os efeitos positivos do potencial empreendedor.

Dentre as pendências ainda a investigar, cinco merecem menção. Primeiro, por mais minuciosa que seja a metodologia que resulta na atribuição de estrelas a um estabelecimento de hospedagem, a existência de relação entre esta classificação e o desempenho organizacional requer mais pesquisa no caso hoteleiro.

Segundo, como as estrelas devem ter sido atribuídas antes de calculado o CEI, também se faz necessário um exame futuro deste aspecto da equação. $\mathrm{Na}$ verdade esta questão é mais ampla no sentido de que avaliar uma cross section de respondentes nada informa sobre a evolução temporal do índice, ponto que só seria adequadamente tratado utilizando-se um estudo empírico com design em coorte (cf. CULTIGIMENEZ et al., 2006).

Terceiro, neste estudo nem sempre foram entrevistados os empreendedores, e sim os executivos encontrados no local da entrevista. Embora o próprio Carland (2001) tenha previsto formatos diferentes de sua escala para diferentes respondentes, não se fez esta distinção nesta pesquisa, o que a rigor seria necessário caso se queira responder adequadamente a questão de saber se o índice capta tanto comportamento executivo (ou gerencial), quanto "empreendedorismo gerencial". Uma forma de atenuar o fato de que neste trabalho a resposta a essa questão tenha sido simplesmente postulada e assumida como válida 
seria entender as respostas aqui obtidas como indicadoras da "mentalidade empreendedora" vigente no estabelecimento pesquisado.

Quarto, um aspecto metodológico ainda a melhorar diz respeito ao tratamento requerido pela natureza da variável dependente: por ser uma variável de contagem, que só assume valores inteiros, o método de estimação adequado não seria o dos MQO (CARVALHO et al., 2011, p. 8).

Finalmente, merece destaque a necessidade de coletar mais dados sobre o estabelecimento hoteleiro (por exemplo, faturamento, número de empregados, data de fundação, dentre outros) de modo a completar o quadro empírico sobre o setor estudado.

Devido a motivos já discutidos em seções anteriores, pode ocorrer que a solução dessas pendências não dependa apenas de tempo disponível para enfrentá-las. Todas estas interrogações demandam atenção própria, deixada para outras ocasiões e outros autores.

\section{Referências}

ANDERSÉN, J. A. Critical examination of the CEO - performance relationship. International Journal of Entrepreneurial Behaviour and Research, v. 16, n. 4, p. 309-328, 2010.

ARAÚJO, E. B. Entrepreneurship e intrapreneurship: uma trajetória literária de 1979 a 1988. RAE, v. 28, n. 4, p. 67-76, 1988.

BLALOCK, H. Social Statistics. 2nd international student edition. Tokyo: McGraw-Hill Kogakusha Ltd., 1972.

CARLAND, J. W.; CARLAND, J. C.; HOY, F. S. An Entrepreneurship Index: an empirical validation. Frontiers of Entrepreneurship Research, v. 25, n. 3, p. 244-265, 1992.
CARLAND, J. C.; CARLAND, J. W. The Theoritetical Bases and Dimensionality of the Carland Entrepreneurship Index. Proceedings of the RISE 96 Conference, University of Jyvaskylâ, Finlândia, 1996.

CARLAND, J. W; CARLAND, J. C.; HOY, F. S. Who is an Entrepreneur? is a question worth asking? American Journal of Small Business, v. 15, n. 3, p. 33-39, 1998.

ENSLEY, M. D. Hunting the heffalump: the theoretical basis and dimensionality of the Carland entrepreneurship index. Academy of Entrepreneurship Journal, v. 7, n. 2, p. 51-84, 2001.

CARVALHO, F. A. de; RESENDE, M.; ALVES, F. J. S.; JORGE, M. J. Diversificação do treinamento em organizações contábeis: uma análise empírica utilizando modelos de contagem. REPEC, v. 5, edição especial, art. 1, p. 122, 2011.

CIDE. Anuário Estatístico do Estado do Rio de Janeiro - 2006. Disponível em www.cide.rj.gov.br. Acesso em 06 de maio de 2012.

COVIN, J. G.; GREEN, K. M.; SLEVIN, D. P. Strategic process effects on the entrepreneurial orientation-sales growth rate relationship. Entrepreneurship Theory and Practice, v. 30, n. 1, p. 57-81, 2006.

CULTI-GIMENEZ， S.; COSTA， M. I.; SCHYPULA, A.; GIMENEZ, F. A. Comportamento empreendedor de alunos do curso de Turismo. Cadernos da Escola de Negócios - UNIBRASIL, v. 4, n. 4, p. 113, 2006.

DORNELAS, J. C. A. Empreendedorismo: transformando ideias em negócios. Rio de Janeiro: Campus, 2001. 
Entrepreneurship e desempenho no setor hoteleiro no Rio de Janeiro: Uma análise empírica utilizando o Índice de Carland

DRUCKER, P. F. Inovação e espírito empreendedor: prática e princípios. São Paulo: Pioneira, 2003. 378 p.

FENG, L. Entrepreneurial orientation and organizational performance: exploring the role of internal resources and external environments. Proceedings of 2010 MASS - International Conference on Management and Service Science, 24 a 26 de agosto de 2010, p. 1-4, 2010.

FERREIRA, J. M.; GIMENEZ, F. A. P.; RAMOS, S. C. Potencial empreendedor e liderança criativa: um estudo com varejistas de materiais de construção de Curitiba-PR. In ENANPAD, 29, 2005, Brasília-DF. Anais, Brasilia: ANPAD, 2005.

FERREIRA， M. P.; SANTOS， J. C.; SERRA, F. A. R.; REIS, N. R. Entrepreneurship research: a bibliometric study of the ENANPADs 1997-2008. REBRAE, v. 3, n. 1, p. 31-47, 2010.

FEUERSCHUTTE, S. G.; GODOI, C. K. Competências empreendedoras: um estudo historiográfico no setor hoteleiro. In ENANPAD, 31, 2007, Rio de Janeiro-RJ. Anais, Rio de Janeiro: ANPAD, 2007.

FILION, L. J. Empreendedorismo: empreendedores e proprietários-gerentes de pequenos negócios. Revista de Administração da USP, v. 34, n. 2, p. 5-28, 1999.

FONSECA, J.; MARTINS, G. Curso de Estatística. 6. ed. São Paulo: Atlas, 1996.

GIMENEZ, F. A. P. Potencial empreendedor: um instrumento para mensuração. Revista de Negócios, v. 9, n. 2, p. 107-116, 2004.

GIMENEZ, F. A. P.; INÁCIO, Jr., E. Investigando o potencial empreendedor e de liderança criativa. In ENANPAD, 26,
2002, Salvador-BA. Anais, Salvador: ENANPAD, 2002.

GIMENEZ, F. A. P.; INÁCIO Jr., E.; SUNSIN, L. A. S. B. Uma investigação sobre a tendência do comportamento empreendedor. In E. C. L. SOUZA (org.), Empreendedorismo - competência essencial para pequenas e médias empresas. Brasília: ANPROTEC, p. 9-28, 2001.

GONÇALVES FILHO, C.; VEIT, M. R.; GONÇALVES, C. A. Mensuração do perfil do potencial empreendedor e seu impacto no desempenho das pequenas empresas. Revista de Negócios, v. 12, n. 3, p. 29 - 44, 2007.

GUJARATI, D. N. Basic Econometrics. New York: McGraw-Hill Book Co. 1988.

HAIR, J.; ANDERSON, R.; TATHAM, R.; BLACK, W. Multivariate Data Analysis. 5. ed. Upper Saddle River: Prentice Hall, 1998.

HONMA, E. T. Competências empreendedoras: estudo de casos múltiplos no setor hoteleiro em Curitiba. Dissertação (Mestrado em Administração), 2007. Pro-grama de Mestrado em Administração - Universidade Federal do Paraná, Curitiba-PR, 2007.

INÁCIO Jr., E. Empreendedorismo e liderança criativa: um estudo com os proprietários-gerentes de empresas incubadas no Estado do Paraná. Maringá, 2002. 137 fls. Dissertação (Mestrado em Administração). Universidade Estadual de Maringá-PR, 2002.

JACKSON, W. T.; VAUGHAN, M. J. The entrepreneurial continuum: a new prescription for future studies. Academy of Entrepreneurship Journal, v. 11, n. 1, p. 9-25, 2005. 
JUDGE, G. G.; CARTER HILL, R.; GRIFFITHS, W. E.; LÜTKEPOHL, H.; LEE, T. C. Introduction to the theory and practice of econometrics. $2^{\text {nd }}$. ed. New York: John Wiley \& Sons, 1988.

KENNEDY, P. A guide to Econometrics. $4^{\text {th }}$. ed. Cambridge, Mass.: MIT Press, 1998.

LOPES Jr., G. S.; SOUZA, E. C. L. Atitude empreendedora em proprietários-gerentes de pequenas empresas - construção de um instrumento de medida. REAd, v. 11, n. 6, 2005.

MORRISON, A. A contextualization of entrepreneurship. International Journal of Entrepreneurial Behaviour and Research, v. 12, n. 4, p. 192-209, 2006.

MUNHON, A. Perfil empreendedor dos empresários associados à ACIL Associação Comercial e Industrial de Londrina. 131 fls. Dissertação (Mestrado em Administração), 2007. Programa de Pós-graduação em Administração Universidade Estadual de Maringá e Universidade Estadual de Londrina. Londrina-PR, 2007.

PEDROSA, M. A.; SANTOS, E. C. L. Atitude empreendedora no setor hoteleiro brasileiro: um estudo em pequenos e grandes hotéis no Distrito Federal. In ENANPAD, 32, 2008, Rio de Janeiro-RJ, Anais, ANPAD: Rio de Janeiro, 2008.

PHILIPS, L.; BLOMME, R. 1973. Analyse Chronologique. Louvain: Vander.

RAUCH, A.; WIKLUND, J.; LUMPKIN, G. T.; FRESE, M. Entrepreneurial orientation and business performance: an assessment of past research and suggestions for the future. Entrepreneurship Theory and Practice, v. 33, May, p. 761-787, 2009.
SCHUMPETER, J. A. Teoria do desenvolvimento econômico. São Paulo: Abril Cultural, 1982 [1934].

SEBRAE - GEM. Pesquisa Global Entrepreneurship Monitor - Relatório Global. Brasília: 2001 a 2006.

SIEGEL, S. Estatística Não-Paramétrica para as Ciências do Comportamento. São Paulo: McGraw-Hill, 1981.

TIMMONS, J. A. The Entrepreneurial Mind. Andover, Mass.: Brick House Publ. Co. 1989.

VEIT, M. R.; GONÇALVES FILHO, C. Mensuração do perfil do potencial empreendedor e seu impacto no desempenho das pequenas empresas. In ENANPAD, 31, 2007, Rio de Janeiro-RJ. Anais. Rio de Janeiro: ANPAD, 2007.

ZHANG， X.; WANG，Y.; YANG，Z.; WANG, Q. X. How corporate entepreneurship impacts market performance: a disaggregated approach based on evidence from China. Proceedings of 2006 ICMIT - IEEE International Conference on the Management of Innovation and Technology, 21 a 23 de junho de 2006, vol. 1, p. 101-105, 2006.

ZHARA, S. A.; JENNINGS, D. F.; KURATKO, D. F. The antecedents and consequences of firm-level entrepreneurship: the state of the field. Entrepreneurship Theory and Practice, v. 24, n. 2, p. 45-65, 1999. 